\title{
Lactobacillus rhamnosus L34 and Lactobacillus casei L39 suppress Clostridium difficile-induced IL-8 production by colonic epithelial cells
}

Prapaporn Boonma ${ }^{1}$, Jennifer K Spinler ${ }^{2,3}$, Susan F Venable ${ }^{2,3}$, James Versalovic ${ }^{2,3}$ and Somying Tumwasorn ${ }^{4^{*}}$

\begin{abstract}
Background: Clostridium difficile is the main cause of hospital-acquired diarrhea and colitis known as C. difficile-associated disease (CDAD).With increased severity and failure of treatment in CDAD, new approaches for prevention and treatment, such as the use of probiotics, are needed. Since the pathogenesis of CDAD involves an inflammatory response with a massive influx of neutrophils recruited by interleukin (IL)-8, this study aimed to investigate the probiotic effects of Lactobacillus spp. on the suppression of IL-8 production in response to C. difficile infection.

Results: We screened Lactobacillus conditioned media from 34 infant fecal isolates for the ability to suppress $C$. difficile-induced IL-8 production from HT-29 cells. Factors produced by two vancomycin-resistant lactobacilli, L. rhamnosus L34 (LR-L34) and L.casei L39 (LC-L39), suppressed the secretion and transcription of IL-8 without inhibiting C. difficile viability or toxin production. Conditioned media from LR-L34 suppressed the activation of phospho-NF-KB with no effect on phospho-C-Jun. However, LC-L39 conditioned media suppressed the activation of both phospho-NF-KB and phospho-C-Jun. Conditioned media from LR-L34 and LC-L39 also decreased the production of C. difficile-induced GM-CSF in HT-29 cells. Immunomodulatory factors present in the conditioned media of both LR-L34 and LC-L39 are heat-stable up to $100^{\circ} \mathrm{C}$ and $>100 \mathrm{kDa}$ in size.
\end{abstract}

Conclusions: Our results suggest that L. rhamnosus L34 and L. casei L39 each produce factors capable of modulating inflammation stimulated by $C$. difficile. These vancomycin-resistant Lactobacillus strains are potential probiotics for treating or preventing CDAD.

Keywords: Lactobacillus, Clostridium difficile, Probiotic, IL-8, Anti-inflammatory

\section{Background}

Clostridium difficile is a gram-positive, spore-forming anaerobe that causes antibiotic-associated diarrhea, colitis, and pseudomembranous colitis in humans $[1,2]$. C. difficile-associated disease (CDAD) is acquired in association with the disruption and alteration of the gut microbiota [3]. The frequency and severity of primary CDAD are increasing; as well as recurrent cases and infections refractory to standard antibiotic therapy [4]. C. difficile toxins, toxin $\mathrm{A}(\mathrm{Tcd} A, 308 \mathrm{kDa})$ and toxin $\mathrm{B}(\mathrm{TcdB}, 270 \mathrm{kDa})$, are the main virulence factors contributing to intestinal tissue damage and severe inflammation [5]. Both toxins disrupt the actin cytoskeleton and tight junctions of intestinal

\footnotetext{
*Correspondence: somying.T@chula.ac.th

${ }^{4}$ Department of Microbiology, Faculty of Medicine, Chulalongkorn University, Bangkok, Thailand

Full list of author information is available at the end of the article
}

epithelial cells [6,7], and cause apoptotic and necrotic cell death $[8,9]$. C. difficile toxins, TcdA and TcdB, induce the release of chemokines, like IL-8, from intestinal epithelial cells [10-12]. In addition to IL-8, TcdA induces human epithelial cells to secrete other CXC chemokines, including growth-related oncogene (GRO)- $\alpha$ and neutrophil activating protein-78 (ENA-78), along with the CC chemokine, monocyte chemoattractant protein (MCP)-1 [12]. The disruption of tight junctions is thought to enable TcdA and TcdB to enter the laminar propria and submucosa to induce immune cells to secrete chemokines, proinflammatory cytokines, and mediators which promote proinflammatory and cytotoxic effects $[4,13]$. Proinflammatory cytokines, especially IL-1 $\beta$, also act on epithelial cells to increase IL-8 secretion and upregulate intercellular adhesion molecule-1 (ICAM-1) expression, leading 
to increased ICAM-1 and neutrophil CD11/CD18 receptordependentneutrophiladhesion [14].

A prominent feature of CDAD results from the release of IL- 8 from intestinal epithelial cells that causes a massive influx of neutrophils into the colonic mucosa $[4,5,15]$. Neutrophil-derived inflammatory mediators exert toxic effects on epithelial cells, causing congestion and edema of the mucosa and epithelial cell damage $[14,16]$. IL-8 is a major CXC chemokine that mediates neutrophil recruitment, activation, and adhesion. IL-8 potency relies on high binding affinity for neutrophil surface receptors, CXCR1 and CXCR2; which activate chemotaxis $[17,18]$ and robust effector functions $[19,20]$, and trigger the upregulation of adhesion molecules CD11/CD18 that facilitate transendothelial migration and subsequent tissue infiltration $[14,21]$.

CDAD is most often associated with the disruption of a healthy intestinal microbiome after the administration of antibiotics [3]. Potential biotherapies for the treatment and prevention of CDAD are probiotics. In particular, candidate probiotics are capable of enhancing microbiome stability, interfering with pathogen activity, modulating the immune system, and are intrinsically resistant to broadspectrum antibiotics [22,23]. Meta-analyses of randomized controlled trials $[24,25]$ support the efficacy of probiotic Saccharomyces boulardii and Lactobacillus rhamnosus GG in the prevention of CDAD. Placebo-controlled clinical trials have shown that lyophilized $S$. boulardii decreased diarrhea associated with $\beta$-lactam antibiotics [26], and when used in combination with metronidazole or vancomycin, $S$. boulardii significantly reduced recurrent episodes in patients with CDAD $[27,28]$. The probiotic effects of $S$. boulardii resulted from a secreted protease that interferes with receptor binding of $C$. difficile toxins $\mathrm{A}$ and $\mathrm{B}$ to brush borders of human colonic epithelial cells [29] and the downstream modulation of host mitogen-activated protein kinase (MAPK) signaling pathway [30]. In vitro studies with probiotic bacteria show that Lactobacillus delbrueckii ssp. bulgaricus B-30892 inhibits the cytotoxic effects and adhesion of $C$. difficile to Caco-2 cells [31], while specific strains of Bifidobacterium spp. and Lactobacillus spp. have antagonistic effects on the production of $C$. difficile toxins $\mathrm{A}$ and $\mathrm{B}$ [32].

In the present study, we hypothesized that specific strains of Lactobacillus species isolated from healthy hosts produce factors that suppress toxigenic $C$. difficile-induced IL-8 production. We investigated the probiotic effect of 34 Lactobacillus infant-fecal isolates on the suppression of IL- 8 production from colonic epithelial cells stimulated by $C$. difficile. Conditioned media of two vancomycin-resistant isolates, L. rhamnosus L34 and L. casei L39, suppressed IL-8 production at the level of transcription without inhibiting $C$. difficile growth or toxin production. Large $(>100 \mathrm{kDa})$ heat-stable, soluble factors are suggested to be responsible for the observed IL-8 suppression.

\section{Results}

Human-derived Lactobacillus spp. produce factors that inhibit IL-8 and GM-CSF production by $C$. difficile-stimulated colonic epithelial cells

Lactobacillus conditioned media (LCM) from thirty-four human-derived Lactobacillus isolates (Additional file 1) were screened for the ability to suppress pro-inflammatory cytokine production from $C$. difficile-stimulated colonic epithelial cells. LCM from 3 of 34 Lactobacillus isolates, $L$. rhamnosus L34 (LR-L34), L. rhamnosus L35 (LR-L35), and L. casei L39 (LC-L39), significantly suppressed IL-8 production by approximately $50 \%$ or greater when compared to media control (Figure 1A). These three IL-8-suppressing isolates did not stimulate IL-8 production when cocultured with HT-29 cells in the absence of C. difficile (data not shown). Only a single isolate of $L$. casei was included in this study (Additional file 1), and the third L. rhamnosus isolate in this collection, strain L31, did not suppress IL-8 in the same assay (Figure 1A). In a previous study [33], we sequenced and compared the genomes of L. rhamnosus L31, L34, and L35. Due to the fact that LR-L34 and LRL35 were isolated from the same host, had similar colony morphology, were nearly identical at the nucleotide level and similarly genetically distinct from strain LR-L31, we determined that they were most likely independent isolates of the same strain. Therefore, the remaining experiments in this study were conducted excluding LR-L35.

LCM from LR-L34 and LC-L39 were screened for effects on fourteen additional cytokines in a multi-plex luminex assay. In addition to IL-8, C. difficile stimulated GM-CSF production, but affected no other cytokines tested (Additional file 2). GM-CSF is an important proinflammatory cytokine that allows neutrophils to persist at sites of inflammation $[34,35]$ and enhances the chemotactic response of neutrophils to IL-8 [36]. In addition to IL-8, LCM from both anti-inflammatory lactobacilli strains significantly inhibited the production of GM-CSF (Figure 1B). LCM from a different strain of a matched species of L. rhamnosus, strain L31, not only had no effect on IL-8 production, but also did not inhibit GM-CSF production in the same assay (Additional file 2).

Further characterization of isolates LR-L34 and LCL39 showed that they are resistant to both vancomycin and metronidazole (both with $\mathrm{MIC}>256 \mu \mathrm{g} / \mathrm{mL}$ ), two drugs commonly used to treat $C$. difficile infection in humans $[37,38]$. The anti-inflammatory effect of soluble factors produced by LR-L34 and LC-L39 is not unique to HT-29 cells as LCM from both strains also suppresses IL8 production greater than $50 \%$ from human colonocytes (Caco-2) stimulated by $C$. difficile (Additional file 3). Trypan blue dye exclusion indicated that HT-29 and Caco-2 


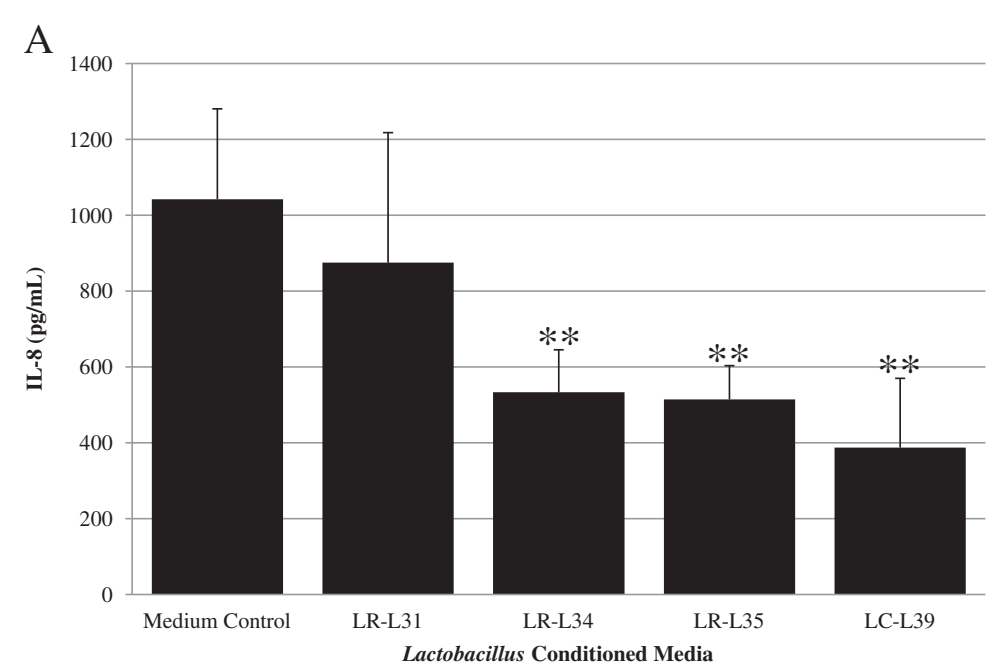

B

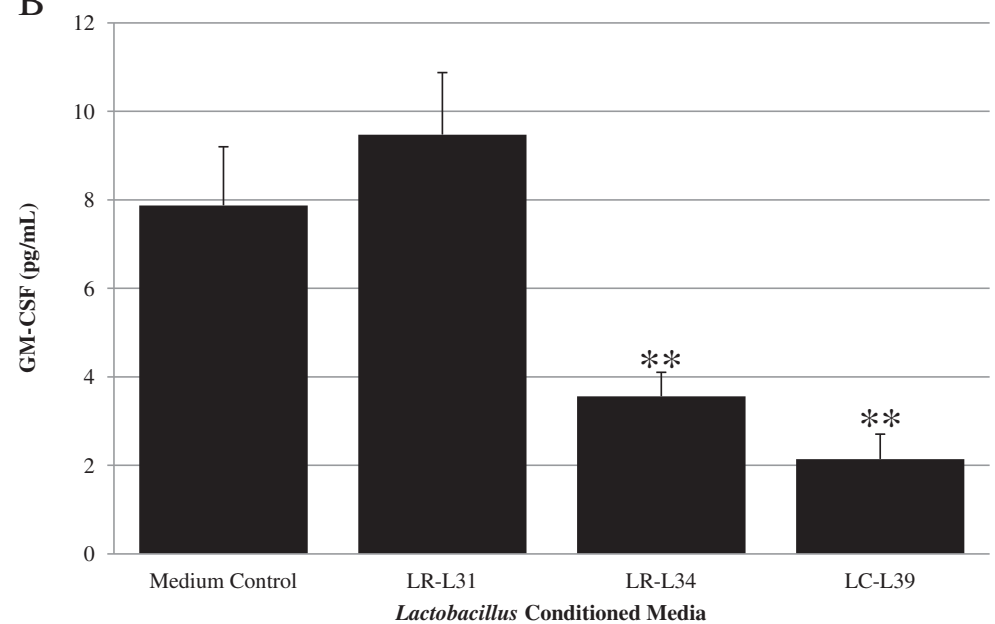

Figure 1 Infant feces-derived Lactobacillus spp. produce factors that suppress pro-inflammatory cytokine production by $C$. difficile-stimulated HT-29 intestinal epithelial cells. LCM from specific strains of human-derived lactobacilli were found to significantly inhibit IL-8 production by HT-29 cells stimulated with C. difficile. Cells were stimulated with C. difficile in the presence of LCM for 24 h. (A) IL-8 production was monitored by ELISA, and (B) GM-CSF production was monitored by a Luminex premixed cytokine assay by Millipore. The results were from three independent experiments in triplicate for figure (A) and one experiment in triplicate for figure (B) and are expressed as the mean \pm SEM, ${ }^{* *} p$-value $<0.01$ as compared to medium control.

cell viability $(>90 \%)$ was not compromised by the presence of any LCM tested (data not shown). Furthermore, neither viability of (Additional file 4) nor toxin production by (Additional file 5) $C$. difficile was negatively affected by the presence of LCM. All further in vitro experimentation was carried out using the $C$. difficile-HT-29 cell co-culture model.

\section{L. rhamnosus L34 and L. casei L39 affect IL-8 gene} transcription through decreased activity of NF-KB and c-Jun The effects of soluble factors produced by LR-L34 and LCL39 on IL-8 transcription were determined by IL-8 genespecific quantitative RT-PCR. C. difficile-stimulated HT-29 cells were treated with LCM for $4 \mathrm{~h}$ prior to total RNA isolation. When compared to media control, treatment with LCM from LR-L34 or LC-L39 resulted in an approximate 0.5 -fold down-regulation $(p$-value $<0.001)$ of IL-8 mRNA concentration relative to gapdh (Figure 2).

Transcriptional regulation of IL-8 is mediated via NF$\kappa \mathrm{B}$ and AP- 1 by the upstream phosphorylation of subunits p65 and c-Jun, which result in the respective activation of NF- $\mathrm{kB}$ and AP-1 and subsequent downstream transcription of IL-8 [39-42]. To determine whether or not LR-L34 or LC-L39 produce factors that affect activation of NFкB or c-Jun, C. difficile-stimulated HT-29 cells were treated with LCM from either LR-L34 or LC-L39 for 15 and $30 \mathrm{~min}$, then were assayed for effects on phosphorylated NF- $\mathrm{kB}$ (p-NF- $\mathrm{kB}$ ) and c-Jun (p-c-Jun) concentrations by western blot. LCM from LR-L34 decreased p-NF- $\mathrm{KB}$ by $47.93 \%$ at $30 \mathrm{~min}$ only ( $p$-value $<0.001$, Figure $3 \mathrm{~A}$ ), 


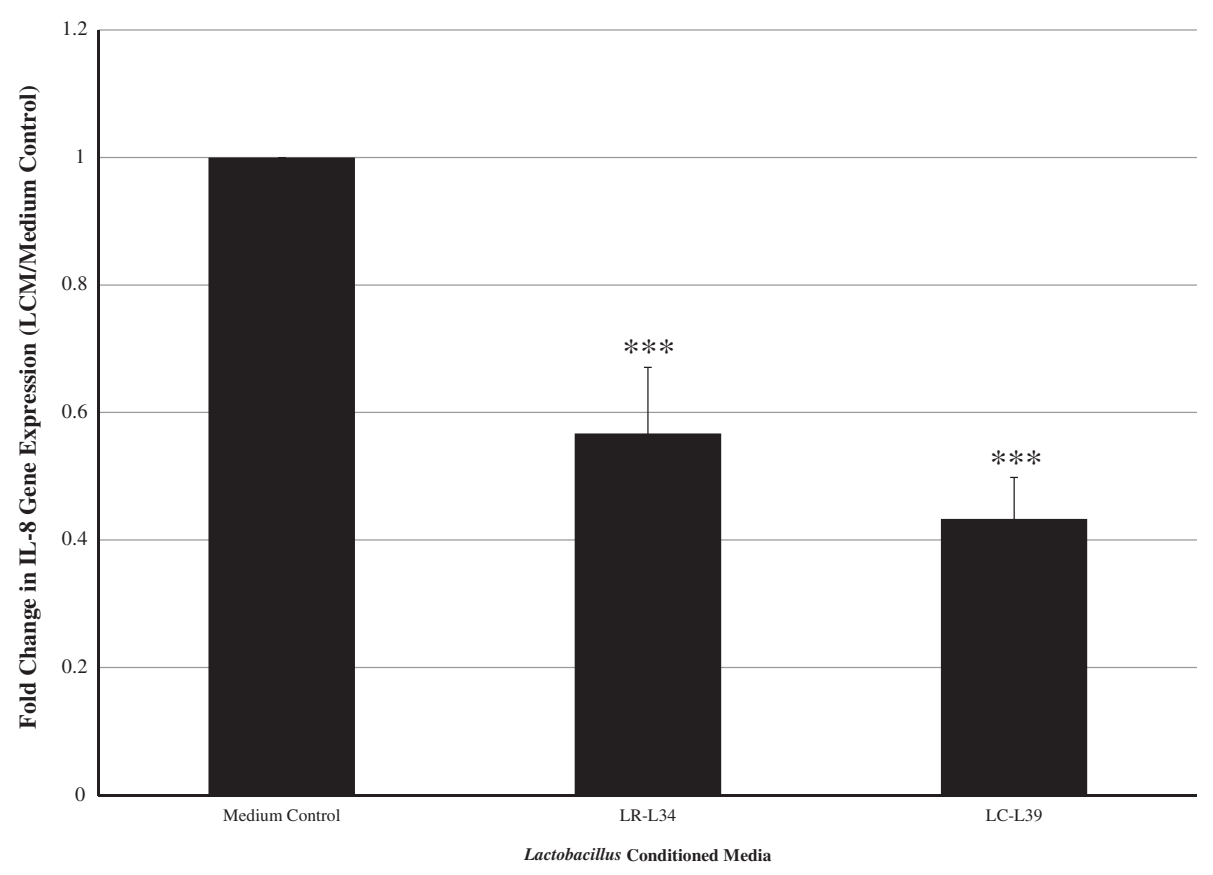

Figure 2 Lactobacillus soluble factors suppress IL-8 transcription in HT-29 cells. IL-8 gene expression was determined in C. difficile-stimulated HT-29 cells after $4 \mathrm{~h}$ incubation with medium control or LCM from either LR-L34 or LC-L39. Quantitative real-time PCR was conducted with primers specific to IL-8 and GAPDH transcripts. Gene expression data were normalized to housekeeping gene, GAPDH. Fold change ratios of IL-8 (LCM strain/medium control) from one experiment in triplicate were calculated, and results represent the mean $\pm \mathrm{SEM},{ }^{* * *} p$-value $<0.001$ as compared to medium control.

and did not affect p-c-Jun at either time point (Figure 3B). A 15 min treatment with LC-L39 LCM resulted in decreased concentrations of p-NF- $\mathrm{kB}(18.62 \%, p$-value $<0.01$, Figure $3 \mathrm{~A})$ and $\mathrm{p}$-c-Jun $(38.19 \%, p$-value $<0.001$, Figure $3 \mathrm{~B})$ while a 30 min treatment resulted in a $43.19 \%$ decrease in p-NF-кB ( $p$-value $<0.001$, Figure $3 \mathrm{~A})$.

The anti-inflammatory factor(s) produced by L. rhamnosus L34 and L. casei L39 is heat-stable and greater than $100 \mathrm{kDa}$ in size

Heat tolerance and size prediction of anti-inflammatory factors in LCM from LR-L34 and LC-L39 were characterized as follows. LCM from LR-L34 and LC-L39 were heated to $100^{\circ} \mathrm{C}$ for $15 \mathrm{~min}, 30 \mathrm{~min}$, and $1 \mathrm{~h}$ and then tested for the ability to suppress $C$. difficile-induced IL-8 production in HT-29 cells. The ability to suppress IL-8 production in this assay was retained at all time points (Figure 4A). Size fractionation of LR-L34 and LC-L39 LCM was performed using $30 \mathrm{kDa}$ and $100 \mathrm{kDa}$ Amicon $^{\circ}$ Centrifugal Filters and filtrates containing factors $<30 \mathrm{kDa}$ and $<100 \mathrm{kDa}$ did not suppress IL- 8 activity, while fractions containing factors $>100 \mathrm{kDa}$ retained the anti-IL-8 activity in each case (Figure 4B).

\section{Discussion}

Standard therapy for treating CDAD with metronidazole and vancomycin is effective, but the association of these drugs with high relapse rates represents a major health problem [43-45]. Recent reports estimate the rate of recurrence after an initial episode of CDAD to be $13-38 \%$ [46-49]. Standard therapy for recurrent CDAD has been modified to include probiotics like L.rhamnosus GG, $L$. plantarum 299v, or S. boulardii which reduce the rate of recurrence around $20-30 \%[28,50,51]$. Health promoting effects of lactobacilli include the stabilization of indigenous microbial populations, protection against intestinal infection, modulation of the immune system, and effects on gene expression in the human mucosa [52-54]. In addition, a recent systematic review and meta-analysis indicated that probiotics given concurrently with antibiotics reduced the risk of antibiotic-associated diarrhea and $C$. difficile infection [55]. A key characteristic of the pathophysiology of CDAD is an inflammatory response with a marked neutrophil accumulation resulting from secreted IL-8 [14-16,21]. Lactobacilli are known to inhibit IL-8 production by intestinal epithelial cells stimulated with bacterium-derived LPS [56] but have not yet been associated with the modulation of $C$. difficile-induced IL-8 production.

We identified two Lactobacillus isolates from a library of infant feces-derived Lactobacillus spp. that can significantly suppress IL- 8 production by $C$. difficile-stimulated HT-29 cells. IL-8 suppression by LR-L34 and LC-L39 did not result from negative effects on $C$. difficile viability as 

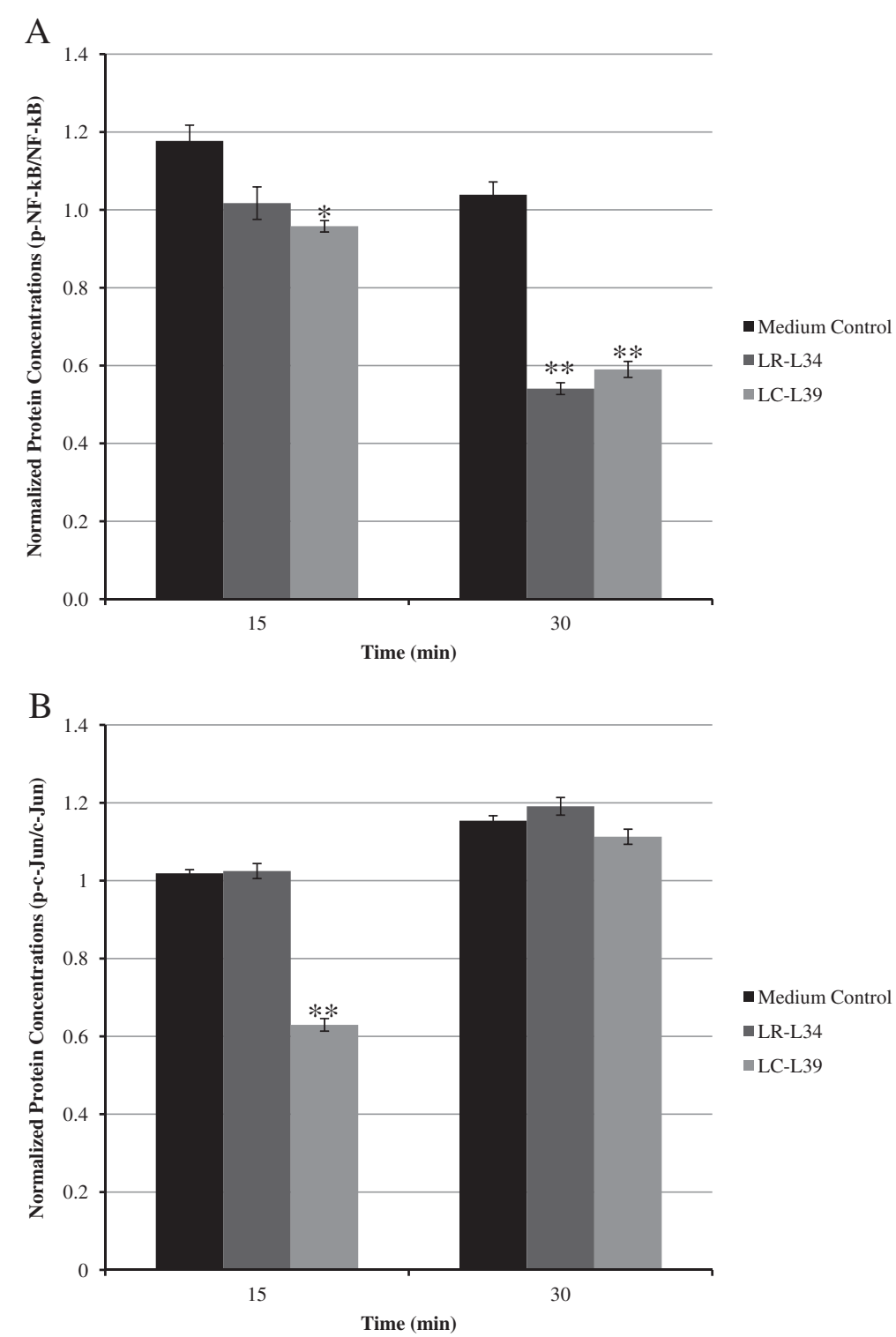

Figure 3 Human-derived Lactobacillus spp. suppress activation of $C$. difficile-induced transcription factors. Concentrations of activated NF-KB (A) and C-Jun (B) were determined by western blot on whole cell lysates of HT-29 cells stimulated with C. difficile with or without medium control or LCM treatment. Concentrations were measured at 15 and 30 min using antibodies corresponding to p-NF-kB p65, NF-KB p65, $\beta$-actin, p-c-Jun, and c-Jun. Relative protein concentrations were determined by densitometry, and activated transcription factors were normalized to their non-activated counterpart ( $\mathrm{p}-\mathrm{NF}-\mathrm{kB}$ p65 (Ser 536) to NF-kB p65; p-c-Jun to c-Jun). The results were from three independent experiments in duplicate and are expressed as the mean \pm SEM, ${ }^{*} p$-value $<0.05$ and ${ }^{* *} p$-value $<0.01$

colony counts from the co-culture supernatants of either C. difficile alone, or in combination with MRS, or LCM from LR-L34 or LC-L39, were not significantly different (Additional file 4). Trejo et al. [32] demonstrated that spent culture supernatants of B. bifidum 5310 and L. plantarum 83114 diminished the production of toxin $\mathrm{A}$ and toxin B by C. difficile ATCC 9689 and clinical isolate 117 . IL-8 suppression by LR-L34 and LC-L39 seems not to result from attenuated toxin production and endocytosis by HT-29 cells. No significant difference of intracellular toxin concentrations in C. difficile and HT-29 cells was seen by LCM treatment as compared to medium control (Additional file 5). However, we cannot exclude the possibility that LCM of LR-L34 and LC-L39 interfere with toxin self-cleavage in the endosome prior to entering the cytosol which induces several downstream inflammatory consequences [57]. It is likely that $C$. difficile-secreted toxins were endocytosed by HT-29 cells as a very small amount of toxin was present in tissue culture medium at $24 \mathrm{~h}$ of the co-culture assay. 

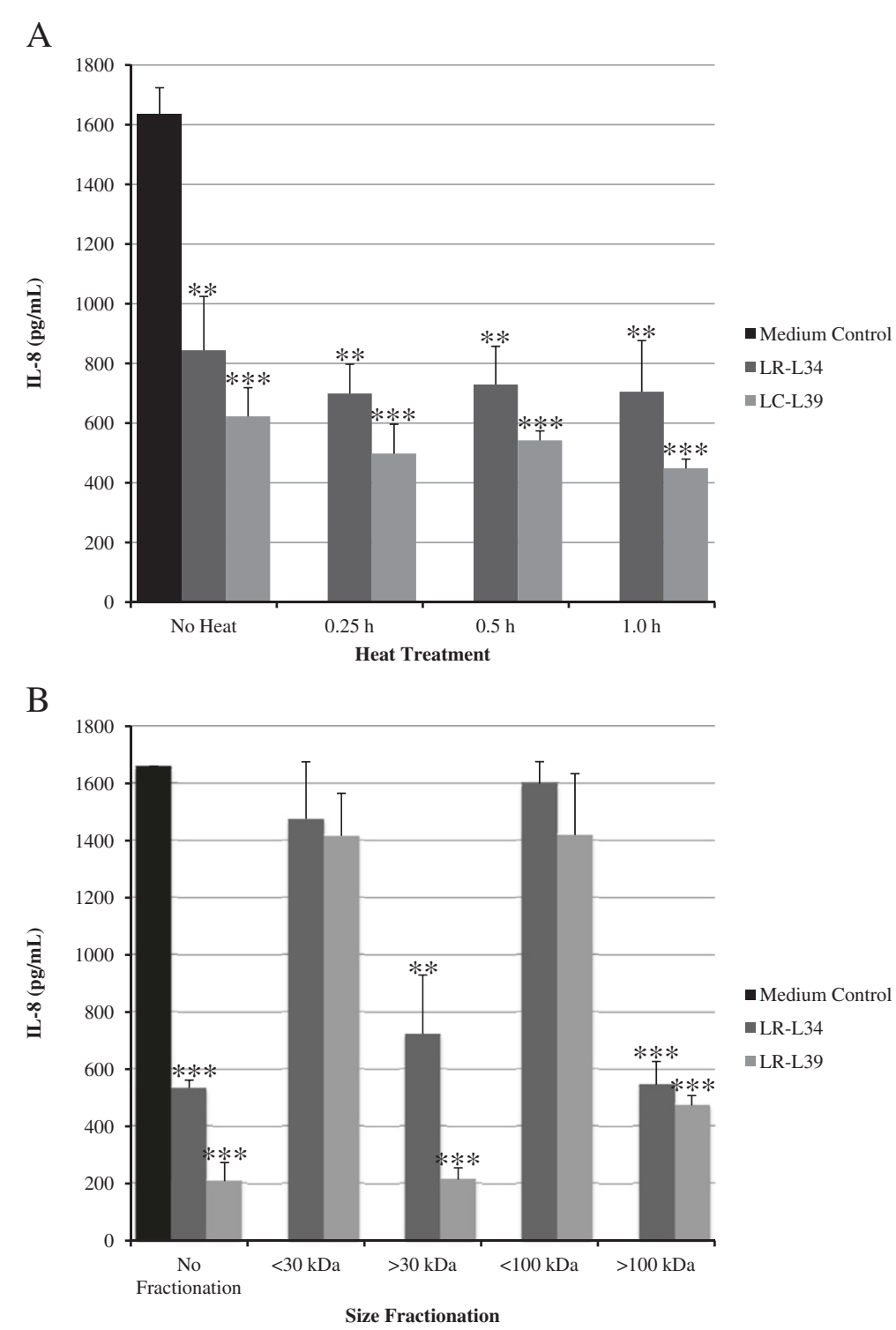

Figure 4 IL-8 suppression by LCM after heat treatment and size fractionation. Soluble factors in LCM from LR-L34 and LC-L39 were assayed for heat stability and size prediction. LCM from L. rhamnosus L34 and L. casei L39 was either heated to boiling for various time points (A) or size fractionated by filtration (B) and the effects on IL-8 production by C. difficile-stimulated HT-29 cells was evaluated by ELISA. The results were from three independent experiments in triplicate and are expressed as the mean \pm SEM, ${ }^{* *} p$-value $<0.01$ and ${ }^{* * *} p$-value $<0.001$.

LR-L34 and LC-L39 suppressed IL-8 gene transcription at $4 \mathrm{~h}$ after co-culture with HT-29 cells which is in agreement with a report of Imaoka et al. [58] for B. bifidum strain Yakult. The IL-8 gene promoter contains binding sites for transcription factors such as NF- $\mathrm{kB}$ and AP-1 [59], which control the transcription of IL-8 in C. difficilestimulated HT-29 colonic epithelial cells [40,60]. LCM from LR-L34 decreased p-NF-kB, and did not affect p-cJun while LC-L39 LCM decreased both of p-NF-kB and $\mathrm{p}$-c-Jun, with greater effects on pNF-kB. Modulation of pro-inflammatory signaling pathways by probiotic bacteria and yeasts have been demonstrated previously. Ma et al.
[61] reported that L. reuteri inhibited TNF-induced IL-8 production in both T84 and HT-29 intestinal epithelial cells by inhibiting nuclear translocation of NF-кB. $S$. boulardii modifies host cell pro-inflammatory signaling pathways during bacterial infection by blocking the activation of NF-kB and MAPK [62-64]. Our data showed that $C$. difficile stimulated GM-CSF production in addition to IL-8 and conditioned media generated from LR-L34 and LC-L39 can also suppress GM-CSF production. The ability to suppress GM-CSF of these lactobacilli potentially enhances their anti-inflammatory effects on C. difficile infection. 
Probiotic factors can vary from organism to organism in regards to activity, size, and stability. Sougioultzis et al. [65] reported that $S$. boulardii probiotic yeast produce a heat stable, $<1 \mathrm{kDa}$ soluble, anti-inflammatory compound that blocks NF-kB activation and NF-kB-mediated IL-8 gene expression in both HT-29 colonic epithelial cells and THP-1 monocytes. L. rhamnosus GG secretes p40 (40 kDa) and p75 $(75 \mathrm{kDa})$ proteins that activate EGFR and downstream PI3K/Akt and PKC signaling that modulate intestinal epithelial cell survival and growth [66]. Castagliuolo et al. [29] reported that a 54-kDa protease of S. boulardii can inhibit the effect of $C$. difficile toxins A and B in HT-29 cells. L. reuteri ATCC PTA 6475 produces the small molecule, histamine, which inhibits TNF production in THP-1 monocytes via PKA and ERK signaling [67]. Active substances in LCM of LR-L34 and LC-L39 were found to be heat-stable and $>100 \mathrm{kDa}$. Although LR-L34 and LC-L39 also inhibit TNF production by THP-1 monocytes, they do not produce histamine (data not shown). Therefore the TNF-suppressive mechanism of action of these lactobacilli must be different from $L$. reuteri, and further investigation is needed to characterize the soluble factors produced by these specific Lactobacillus isolates. The discovery of vancomycin-resistant LR-L34 and LC-L39 with IL-8suppressing ability in this study offers us potential probiotic strains for combating CDAD. These strains may harbor other probiotic properties, including the ability to replenish normal microbiota, a key factor for treating CDAD as shown by the recent successes with intestinal microbiome transplant therapies $[68,69]$.

\section{Conclusions}

We have demonstrated the probiotic effect of two vancomycin-resistant strains, $L$. rhamnosus L34 and $L$. casei L39, on the suppression of IL-8 production from $C$. difficile-stimulated colonic epithelial cells. These strains suppressed IL-8 production by inhibiting activation of transcription factors for IL-8 gene expression without inhibiting $C$. difficile growth or toxin production. Our data also suggest that heat-stable, $>100 \mathrm{kDa}$ factors are responsible for IL-8 suppression. These vancomycin-resistant Lactobacillus strains are potential probiotics for treating or preventing CDAD.

\section{Methods}

\section{Bacterial strains and culture conditions}

Thirty-four Lactobacillus spp. isolated from infant feces were analyzed in this study (Additional file 1). All lactobacilli were routinely cultured in an anaerobic chamber (Concept Plus, Ruskinn Technology, UK) (10\% $\mathrm{CO}_{2}$, $10 \% \mathrm{H}_{2}$, and $80 \% \mathrm{~N}_{2}$ ) for $24 \mathrm{~h}$ at $37^{\circ} \mathrm{C}$ in de Man, Rogosa, Sharpe (MRS) medium (Oxoid, England).

A C. difficile isolate, designated strain B2-CU-0001-54 was obtained from feces of an infected patient positive for $C$. difficile toxins A and B by VIDAS ${ }^{\oplus}$ Clostridium difficile A \& B (Biomérieux, France) at the Department of Microbiology, Faculty of Medicine, Chulalongkorn University. This strain is positive for TcdA and TcdB as determined by PCR for toxin A and B genes [70] and the reactivity with mouse anti-TcdA and anti-TcdB monoclonal antibodies (Meridian Life Science, Inc.). C. difficile B2-CU-0001-54 was routinely cultured anaerobically on Brucella agar (Oxoid, England) at $37^{\circ} \mathrm{C}$ for $48 \mathrm{~h}$. Cells were harvested, re-suspended in McCoy's medium, and adjusted to a McFarland 6 standard $\left(1.8 \times 10^{9}\right.$ cells $\left./ \mathrm{mL}\right)$ prior to coculture with HT-29 cells. This study was approved by the Ethics Committee of Faculty of Medicine, Chulalongkorn University, Bangkok, Thailand (COA no.617/2011, IRB no.246/54). Written informed parental consent for fecal samples was obtained from participants.

\section{Minimum inhibitory concentration assay}

The minimum inhibitory concentration of vancomycin on LR-L34 and LC-L39 was determined by the broth microdilution procedure as previously described [71]. Briefly, $100 \mu \mathrm{l}$ of lactobacilli (final concentration $1 \times 10^{6} \mathrm{CFU} / \mathrm{mL}$ or $1 \times 10^{5} \mathrm{CFU} /$ well) were inoculated into the wells of a 96 well plate containing $100 \mu \mathrm{l}$ of vancomycin in serial 2-fold dilutions from 256 to $0.125 \mu \mathrm{g} / \mathrm{mL}$, then were cultured anaerobically for $48 \mathrm{~h}$. Optical density was measured at $600 \mathrm{~nm}$ using a microplate reader Multiskan ${ }^{\bullet}$ EX (Thermo Scientific, USA). The results were compared with growth control (lactobacilli alone) and the endpoint of $\mathrm{MIC}$ is the concentration where no growth or a reduction in growth by $90 \%$, is observed.

\section{Preparation of Lactobacillus conditioned media}

LCM were prepared as previously described [72]. Briefly, $24 \mathrm{~h}$ cultures were adjusted to an $\mathrm{OD}_{600} 0.1$ and incubated anaerobically for $48 \mathrm{~h}$. Supernatants were collected, filtered with $0.22 \mu \mathrm{m}$ Millex-GV Filter Units (Millipore, USA), and $500 \mu \mathrm{L}$ aliquots were concentrated by Eppendorf Vacufuge ${ }^{\oplus}$ vacuum concentrator (Eppendorf North America, USA) at $60^{\circ} \mathrm{C}$ for $2.5 \mathrm{~h}$. Pellets were resuspended in an equal volume of McCoy's 5a modified medium (Gibco-Invitrogen, Carlsbad, CA, USA) or Eagle's Minimal Essential Medium (Gibco-Invitrogen, USA) and stored at $-20^{\circ} \mathrm{C}$ until further analysis.

\section{Cell lines and culture conditions}

Human colonic epithelial cells, HT-29 or Caco-2, were obtained from the American Type Culture Collection (ATCC HTB-38 and HTB-37, respectively; Manassas, VA, USA). HT-29 cells were maintained in McCoy's 5a modified medium supplemented with $10 \%(\mathrm{v} / \mathrm{v})$ heat-inactivated fetal bovine serum (Gibco-Invitrogen, USA) at $37^{\circ} \mathrm{C}$ under $5 \% \mathrm{CO}_{2}$ for $48 \mathrm{~h}$. Caco-2 cells were maintained in Eagle's Minimal Essential Medium supplemented with 20\% (v/v) 
heat-inactivated fetal bovine serum at $37^{\circ} \mathrm{C}$ under $5 \%$ $\mathrm{CO}_{2}$ for $72 \mathrm{~h}$. Adherent cells were detached with $0.25 \%$ (v/v) Trypsin (Gibco-Invitrogen, USA) in $1 \mathrm{mM}$ EDTA (Gibco-Invitrogen, USA) and resuspended in their respective medium. Resuspensions of each cell type were used in subsequent $C$. difficile co-culture assays.

\section{LCM treatment and C. difficile co-culture with colonic epithelial cells}

Colonic epithelial cells were treated with LCM and stimulated to produce IL- 8 by co-culture with $C$. difficile. HT-29 $\left(2.0 \times 10^{4}\right.$ cells $)$ or Caco- 2 cells $\left(5.0 \times 10^{4}\right.$ cells $)$ were pre-incubated for $24 \mathrm{~h}$ in a 96-well format as described above. LCM $(5 \% \mathrm{v} / \mathrm{v})$ was added with or without the subsequent addition of viable $C$. difficile B2-CU-0001$54\left(6.0 \times 10^{6} \mathrm{CFU} /\right.$ well with HT-29 cells or $4.5 \times 10^{7} \mathrm{CFU} /$ well with Caco- 2 cells) and co-incubated for an additional $24 \mathrm{~h}$. Cell culture supernatants were collected by centrifugation $\left(125 \times \mathrm{g}, 4^{\circ} \mathrm{C}\right.$ for $\left.7 \mathrm{~min}\right)$ and stored at $-20^{\circ} \mathrm{C}$ until further use.

\section{Effects of LCM on C. difficile viability}

To ensure IL-8 suppression did not result from the antagonism of $C$. difficile growth by soluble factors in LCM, $C$. difficile B2-CU-0001-54 was assayed for viability after coincubation with LCM and HT-29 cells. Briefly, co-culture supernatants were serially diluted and cultured anaerobically on Brucella agar (Oxoid, England) at $37^{\circ} \mathrm{C}$ for $48 \mathrm{~h}$. Counts of isolated $C$. difficile B2-CU-0001-54 colonies from co-culture assays with and without LCM treatment were compared.

Effects of LCM on C. difficile toxins in the co-culture assay To determine whether Lactobacillus spp. produce factors that suppress $C$. difficile toxin secretion, intracellular and secreted toxin concentrations from co-culture assays were determined as previously described [32] with the following modifications. Secreted toxin was measured from LCMtreated, C.difficile-stimulated HT-29 cell supernatants, which were concentrated 10 -fold by speed vacuum drying and spotted onto polyvinylidene fluoride (PVDF) membranes (Bio-Rad, Philadelphia, USA). Blocked membranes were incubated in succession with mouse anti-TcdA or anti-TcdB monoclonal antibodies (Meridian Life Science, Inc.), biotinylated goat anti-mouse IgG, and extravidinalkaline phosphatase (Sigma-Aldrich, St. Louis, MO, USA). The presence of toxin was determined colorimetrically with nitro blue tetrazolium/5-bromo-4-chloro-3-indolylphosphate (NBT/BCIP) solution (Sigma-Aldrich, St. Louis, MO, USA). Intracellular toxin concentrations were determined from LCM-treated, C.difficile-stimulated HT-29 cell pellets. Pellets from $20 \mathrm{ml}$ of cell culture were washed, resuspended in $2 \mathrm{ml}$ cell culture medium, and lysed by sonication (Vibra-Cell ${ }^{\mathrm{Ts}}$, Sonics \& Materials, Inc., USA).
Cell lysates were collected, $100 \mu \mathrm{l}$ spotted onto PVDF membranes, and analyzed for the presence of toxin as described above. Toxin concentrations were calculated by ChemiDoc $^{\text {TM }}$ XRS (Bio-Rad, Philadelphia, USA).

\section{Effects of LCM on cytokine production by ELISA and Luminex assays}

Supernatants from co-culture assays were tested for the effects of soluble factors produced by Lactobacillus on IL-8 production and other related cytokines. IL-8 concentrations in LCM-treated, C. difficile-stimulated HT29 or Caco-2 cell co-culture supernatants were measured using a Human CXCL8/IL-8 ELISA kit (R\&D Systems, Minneapolis, MN) according to the manufacturer's instructions. To determine whether Lactobacillus spp. can modulate cytokines other than IL-8 in this assay, cell supernatants from $C$. difficile-stimulated HT-29 cells in the presence or absence of LCM were screened by a Human Cytokine/Chemokine-Premixed 14-plex kit (Millipore, Billerica, MA) in a Luminex 100 system (Luminex Corporation, Austin, TX) for quantification of the analytes GM-CSF, IFN- $\gamma$, IL-1 $\beta$, IL-2, IL-4, IL-5, IL-6, IL-7, IL-8, IL-10, IL-12 (p70), IL-13, MCP-1, and TNF- $\alpha$. Analytes at concentrations exceeding the minimum detectable dose were evaluated and raw data were obtained with MasterPlex CT version 1.2.0.7 and analyzed with MasterPlex QT version 5.0.0.73 (Hitachi MiraiBio, San Francisco, CA).

\section{Analysis of IL-8 gene transcription by $\mathrm{qPCR}$}

The effects of LCM on the transcription of IL- 8 were determined by qPCR as previously described [58] with the following modifications. HT-29 cells $\left(8.0 \times 10^{5}\right.$ cells $)$ were pre-incubated in a 24-well format as outlined above. Cells were LCM-treated $(5 \% \mathrm{v} / \mathrm{v})$ with or without the subsequent addition of viable $C$. difficile B2-CU-

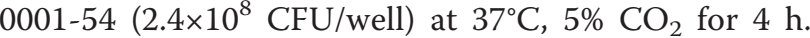
Total RNA was extracted from HT-29 cells using TRIzol reagent (Invitrogen, USA) according to the manufacturer's instructions. Synthesis of cDNA was completed using the SuperScript ${ }^{\oplus}$ VILO $^{\mathrm{Tm}}$ cDNA Synthesis kit (Invitrogen), and qPCR was performed in a LightCycler ${ }^{\circledR} 2.0$ (Roche, Germany) for 45 cycles of: $15 \mathrm{~s}$ at $94^{\circ} \mathrm{C}, 25 \mathrm{~s}$ at $60^{\circ} \mathrm{C}$, and $25 \mathrm{~s}$ at $72^{\circ} \mathrm{C}$. The amplified product was detected using Light Cycler $^{\oplus}$ Fast Start DNA Master ${ }^{\text {PLUS }}$ SYBR Green I (Roche, Germany) at $530 \mathrm{~nm}$. The following primers were used to amplify cDNA fragments: IL- 8 forward primer ( $5^{\prime}$-ACACTGCGCCAACACAGAAATTA$3^{\prime}$ ), IL-8 reverse primer (5'-TTTGCTTGAAGTTTCA CTGGCATC-3'); GAPDH forward primer (5'-GCAC CGTCAAGGCTGAGAAC-3'), GAPDH reverse primer (5'-ATGGTGGTGAAGACGCCAGT-3'). IL-8 gene expression, relative to $\mathrm{GAPDH}$, was calculated according to the $2^{-\Delta \Delta C \mathrm{p}}$ method [73]. 


\section{Examination of cell signaling pathways by quantitative western blot}

Changes in the NF- $\mathrm{kB}$ signaling pathway coordinating with LCM treatment were analyzed by western blot as previously described [30] with minor modifications. LCMtreated, C. difficile-stimulated HT-29 cells were lysed in a radioimmunoprecipitation assay (RIPA) buffer $(50 \mathrm{mM}$ TrisHCl, pH7.4, $150 \mathrm{mM} \mathrm{NaCl}, 10 \% \mathrm{NP}-40,0.5 \% \mathrm{Na}-$ DOC, $0.1 \%$ SDS). Protein concentrations from cell lysates were measured using the Pierce ${ }^{\bullet}$ BCA protein assay kit (Pierce Biotechnology, Illinois, USA). Cell extracts were fractionated by $10 \%$ sodium dodecyl sulfate polyacrylamide gel electrophoresis (SDS-PAGE), transferred onto PVDF membranes (Bio-Rad, Philadelphia, USA), and blocked (10\% non-fat milk in TBST (50 mM Tris, pH 7.5, $0.15 \mathrm{M} \mathrm{NaCl}, 0.05 \%$ Tween 20). Blocked membranes were incubated with mouse antibodies against NF-kB (p65), phospho-NF-kB (p65), c-Jun, phospho-c-Jun and $\beta$-actin (Santa Cruz Biotechnology, California, USA), washed with TBST and treated with horseradish peroxidase-labeled goat anti-mouse secondary antibodies for $1 \mathrm{~h}$. Peroxidase signals were detected and imaged by ChemiDoc ${ }^{\text {Tix }}$ XRS (Bio-Rad, Philadelphia, USA).

\section{Characterization of IL-8 suppressive factors in LCM}

Lactobacillus anti-inflammatory factors responsible for suppressing IL-8 production from $C$. difficile-stimulated colonic epithelial cells were assessed for thermal stability and size estimation. Heat stability was assessed by heating LCM to $100^{\circ} \mathrm{C}$ for $15 \mathrm{~min}, 30 \mathrm{~min}$, and $1 \mathrm{~h}$. The sizes of active factors present in LCM were estimated by $30 \mathrm{kDa}$ and $100 \mathrm{kDaAmicon}^{\circ}$ Ultra-4 Centrifugal Filters (Merck, Massachusetts, USA). After each treatment, LCM was tested for the ability to suppress IL- 8 production from $C$. difficile-treated HT-29 cells using techniques outlined above.

\section{Statistical analyses}

All experiments were performed at least in triplicate and the results were reported as mean \pm standard deviation or standard error of mean (SEM). The data were analyzed in Microsoft Excel using the Student's $t$-test with one-tailed distribution and considered statistically significant at a $p$-value $\leq 0.05$, unless otherwise stated.

\section{Additional files}

Additional file 1: Infant feces-derived Lactobacillus spp. used in this study.

Additional file 2: Production of cytokines and chemokines by $C$. difficile-stimulated HT-29 cells.

Additional file 3: Infant feces-derived Lactobacillus spp. produce factors that suppress pro-inflammatory cytokine production by $C$. difficile-stimulated Caco-2 intestinal epithelial cells. LCM from human-derived lactobacilli were found to significantly inhibit IL-8 production from Caco-2 cells stimulated with $C$. difficile. Cells were stimulated with C. difficile in the presence of LCM for $24 \mathrm{~h}$ and IL-8 production was monitored by ELISA. The results were from three independent experiments in triplicate and are expressed as the mean \pm SEM, ${ }^{* *} p$-value $<0.01$ as compared to medium control.

Additional file 4: $C$. difficile viability was not affected by Lactobacillus conditioned media. IL-8 suppression did not result from LCM effects on the antagonism of C. difficile growth. C. difficile B2-CU-0001-54 was assayed for viability after co-incubation with LCM and HT-29 cells. Counts of isolated C. difficile B2-CU-0001-54 colonies from co-culture assays with and without LCM treatment from three independent experiments in triplicate were compared and results are reported as mean \pm SD. No significant difference in viability of $C$. difficile was seen by LCM treatment as compared to medium control.

Additional file 5: Lactobacillus conditioned media had no effect on C. difficile toxins in co-culture assay. $\mathrm{LL}-8$ suppression did not result from attenuated toxin production and endocytosis to HT-29 cells.

Extracellular and intracellular toxin concentrations were determined from LCM-treated, C. difficile-stimulated HT-29 cells. Cell culture supernatants or lysates of C. difficile and HT-29 cells were collected, spotted onto PVDF membranes and assayed in succession with mouse anti-TcdA or anti-TcdB monoclonal antibodies. The presence of toxin was determined colorimetrically and toxin concentrations were calculated by ChemiDoc ${ }^{\text {TM }}$ XRS (Bio-Rad, Philadelphia, USA). The results were from three independent experiments in triplicate and are expressed as the mean \pm SEM. No significant difference in intracellular toxin concentrations was seen by LCM treatment as compared to medium control. (A) Whole cell lysates, (B) culture supernatant of HT-29 cells, (C) the ratio between spot intensity of $\mathbf{C}$. difficile co-culture with LCM and C. difficile with MRS.

\section{Competing interests}

The authors declare that they have no competing interests.

\section{Authors' contributions}

JKS, JV, and ST conceived and designed the study. PB designed and performed the experiments. SV carried out Luminex assay. JKS, JV, and ST supervised and provide funding for the research. PB, JKS, and ST wrote the manuscript. All authors read and approved the final manuscript.

\section{Acknowledgements}

We would like to graciously acknowledge Tor Savidge for his advice, guidance, and generosity, and extend our gratitude to both the Texas Children's Microbiome Center and the Functional Genomics \& Microbiome Core for providing equipment and resources for a fruitful collaboration. This work was supported by the Thailand Research Fund through the Royal Golden Jubilee PhD Program (PHD/0295/2550 to PB); the Thai Government Research Budget for Fiscal year 2009 and 2010; the Rachadapisek Sompoj research fund, Faculty of Medicine, Chulalongkorn University (Grant No. RA51/1and RA55/20 to ST). Funding was also provided in part by the Texas Children's Microbiome Center, Department of Pathology at Texas Children's Hospital; and the National Institutes of Health, National Cancer Institute (Grant No. U01 CA170930 to JV); by the National Institute of Diabetes and Digestive and Kidney Diseases (Grant Nos. UH3 DK083990 to JV, P30 DK56338, and R01 DK065075 to JV); and by the National Center for Complementary and Alternative Medicine (Grant No. R01 AT004326 to JV).

\section{Author details}

${ }^{1}$ Interdisciplinary Program of Medical Microbiology, Graduate School, Chulalongkorn University, Bangkok, Thailand. ${ }^{2} T e x a s$ Children's Microbiome Center, Department of Pathology, Texas Children's Hospital, Houston, Texas, USA. ${ }^{3}$ Department of Pathology \& Immunology, Baylor College of Medicine, Houston, Texas, USA. ${ }^{4}$ Department of Microbiology, Faculty of Medicine, Chulalongkorn University, Bangkok, Thailand. 


\section{References}

1. Kelly CP, Pothoulakis C, LaMont JT: Clostridium difficile colitis. N Engl J Med 1994, 330(4):257-262.

2. Kelly CP, LaMont JT: Clostridium difficile infection. Annu Rev Med 1998, 49:375-390

3. De La Cochetiere MF, Durand T, Lalande V, Petit JC, Potel G, Beaugerie L: Effect of antibiotic therapy on human fecal microbiota and the relation to the development of Clostridium difficile. Microb Ecol 2008, 56(3):395-402.

4. Rupnik M, Wilcox MH, Gerding DN: Clostridium difficile infection: new developments in epidemiology and pathogenesis. Nat Rev Microbiol 2009, 7(7):526-536.

5. Voth DE, Ballard JD: Clostridium difficile toxins: mechanism of action and role in disease. Clin Microbiol Rev 2005, 18(2):247-263.

6. Hippenstiel S, Tannert-Otto S, Vollrath N, Krull M, Just I, Aktories K von Eichel-Streiber C, Suttorp N: Glucosylation of small GTP-binding Rho proteins disrupts endothelial barrier function. Am J Physio/ 1997 272(1 Pt 1):L38-L43.

7. Nusrat $A$, von Eichel-Streiber $C$, Turner JR, Verkade $P$, Madara JL, Parkos CA: Clostridium difficile toxins disrupt epithelial barrier function by altering membrane microdomain localization of tight junction proteins. Infect Immun 2001, 69(3):1329-1336.

8. Brito GA, Fujji J, Carneiro-Filho BA, Lima AA, Obrig T, Guerrant RL: Mechanism of Clostridium difficile toxin A-induced apoptosis in T84 cells. J Infect Dis 2002, 186(10):1438-1447.

9. Riegler M, Sedivy R, Pothoulakis C, Hamilton G, Zacherl J, Bischof G, Cosentini E, Feil W, Schiessel R, LaMont JT, Wenzl E: Clostridium difficile toxin $B$ is more potent than toxin $A$ in damaging human colonic epithelium in vitro. J Clin Invest 1995, 95(5):2004-2011.

10. Mahida YR, Makh S, Hyde S, Gray T, Borriello SP: Effect of Clostridium difficile toxin $A$ on human intestinal epithelial cells: induction of interleukin 8 production and apoptosis after cell detachment. Gut 1996, 38(3):337-347

11. Branka JE, Vallette G, Jarry A, Bou-Hanna C, Lemarre P, Van PN, Laboisse CL: Early functional effects of Clostridium difficile toxin A on human colonocytes. Gastroenterology 1997, 112(6):1887-1894.

12. Kim JM, Kim JS, Jun HC, Oh YK, Song IS, Kim CY: Differential expression and polarized secretion of CXC and CC chemokines by human intestinal epithelial cancer cell lines in response to Clostridium difficile toxin A. Microbiol Immunol 2002, 46(5):333-342.

13. Sun $X$, Savidge $T$, Feng $H$ : The enterotoxicity of Clostridium difficile toxins. Toxins (Basel) 2010, 2(7):1848-1880.

14. Kelly CP, Keates S, Siegenberg D, Linevsky JK, Pothoulakis C, Brady HR: IL-8 secretion and neutrophil activation by HT-29 colonic epithelial cells. Am J Physiol 1994, 267(6 Pt 1):G991-G997.

15. Ludwig A, Petersen F, Zahn S, Gotze O, Schroder JM, Flad HD, Brandt E: The CXC-chemokine neutrophil-activating peptide-2 induces two distinct optima of neutrophil chemotaxis by differential interaction with interleukin-8 receptors CXCR-1 and CXCR-2. Blood 1997, 90(11):4588-4597.

16. Castagliuolo I, Keates AC, Wang CC, Pasha A, Valenick L, Kelly CP, Nikulasson ST, LaMont JT, Pothoulakis C: Clostridium difficile toxin A stimulates macrophage-inflammatory protein-2 production in rat intestinal epithelial cells. J Immunol 1998, 160(12):6039-6045.

17. Hammond ME, Lapointe GR, Feucht PH, Hilt S, Gallegos CA, Gordon CA, Giedlin MA, Mullenbach G, Tekamp-Olson P: IL-8 induces neutrophil chemotaxis predominantly via type I IL-8 receptors. J Immunol 1995, 155(3):1428-1433.

18. Wu L, Ruffing N, Shi X, Newman W, Soler D, Mackay CR, Qin S: Discrete steps in binding and signaling of interleukin-8 with its receptor. J Biol Chem 1996, 271(49):31202-31209.

19. Petersen F, Flad HD, Brandt E: Neutrophil-activating peptides NAP-2 and IL-8 bind to the same sites on neutrophils but interact in different ways. Discrepancies in binding affinities, receptor densities, and biologic effects. J Immunol 1994, 152(5):2467-2478.

20. Walz A, Meloni F, Clark-Lewis I, von Tscharner V, Baggiolini M: [Ca2+]i changes and respiratory burst in human neutrophils and monocytes induced by NAP-1/interleukin-8, NAP-2, and gro/MGSA. J Leukoc Biol 1991, 50(3):279-286.

21. Detmers PA, Powell DE, Walz A, Clark-Lewis I, Baggiolini M, Cohn ZA Differential effects of neutrophil-activating peptide $1 / \mathrm{IL}-8$ and its homologues on leukocyte adhesion and phagocytosis. J Immunol 1991, 147(12):4211-4217.
22. O'Hara AM, O'Regan P, Fanning A, O'Mahony C, Macsharry J, Lyons A, Bienenstock J, O'Mahony L, Shanahan F: Functional modulation of human intestinal epithelial cell responses by Bifidobacterium infantis and Lactobacillus salivarius. Immunology 2006, 118(2):202-215.

23. Ng SC, Hart AL, Kamm MA, Stagg AJ, Knight SC: Mechanisms of action of probiotics: recent advances. Inflamm Bowel Dis 2009, 15(2):300-310.

24. McFarland LV: Meta-analysis of probiotics for the prevention of antibiotic associated diarrhea and the treatment of Clostridium difficile disease. Am J Gastroenterol 2006, 101(4):812-822.

25. Hempel S, Newberry SJ, Maher AR, Wang Z, Miles JN, Shanman R Johnsen B, Shekelle PG: Probiotics for the prevention and treatment of antibiotic-associated diarrhea: a systematic review and meta-analysis. JAMA 2012, 307(18):1959-1969.

26. McFarland LV, Surawicz CM, Greenberg RN, Elmer GW, Moyer KA, Melcher SA, Bowen KE, Cox JL: Prevention of beta-lactam-associated diarrhea by Saccharomyces boulardii compared with placebo. Am J Gastroenterol 1995, 90(3):439-448.

27. McFarland LV, Surawicz CM, Greenberg RN, Fekety R, Elmer GW, Moyer KA, Melcher SA, Bowen KE, Cox JL, Noorani Z, Harrington G, Rubin M, Greenwald D: A randomized placebo-controlled trial of Saccharomyces boulardii in combination with standard antibiotics for Clostridium difficile disease. JAMA 1994, 271(24):1913-1918.

28. Kyne L, Kelly CP: Recurrent Clostridium difficile diarrhoea. Gut 2001, 49(1):152-153

29. Castagliuolo I, Riegler MF, Valenick L, LaMont JT, Pothoulakis C: Saccharomyces boulardii protease inhibits the effects of Clostridium difficile toxins $\mathrm{A}$ and $\mathrm{B}$ in human colonic mucosa. Infect Immun 1999, 67(1):302-307.

30. Chen X, Kokkotou EG, Mustafa N, Bhaskar KR, Sougioultzis S, O'Brien M, Pothoulakis C, Kelly CP: Saccharomyces boulardii inhibits ERK1/2 mitogen-activated protein kinase activation both in vitro and in vivo and protects against Clostridium difficile toxin A-induced enteritis. J Biol Chem 2006, 281(34):24449-24454.

31. Banerjee P, Merkel GJ, Bhunia AK: Lactobacillus delbrueckii ssp. bulgaricus B-30892 can inhibit cytotoxic effects and adhesion of pathogenic Clostridium difficile to Caco-2 cells. Gut Pathog 2009, 1(1):8

32. Trejo FM, Perez PF, De Antoni GL: Co-culture with potentially probiotic microorganisms antagonises virulence factors of Clostridium difficile in vitro. Antonie Van Leeuwenhoek 2010, 98(1):19-29.

33. Boonma P, Spinler JK, Qin X, Jittaprasatsin C, Muzny DM, Doddapaneni H, Gibbs R, Petrosino J, Tumwasorn S, Versalovic J: Draft genome sequences and description of Lactobacillus rhamnosus strains L31, L34, and L35. Stand Genomic Sci 2014. In press.

34. Hercus TR, Thomas D, Guthridge MA, Ekert PG, King-Scott J, Parker MW, Lopez AF: The granulocyte-macrophage colony-stimulating factor receptor: linking its structure to cell signaling and its role in disease. Blood 2009, 114(7):1289-1298.

35. Brach MA, de Vos S, Gruss HJ, Herrmann F: Prolongation of survival of human polymorphonuclear neutrophils by granulocyte-macrophage colony-stimulating factor is caused by inhibition of programmed cell death. Blood 1992, 80(11):2920-2924.

36. Shen L, Smith JM, Shen Z, Hussey SB, Wira CR, Fanger MW: Differential regulation of neutrophil chemotaxis to IL-8 and fMLP by GM-CSF: lack of direct effect of oestradiol. Immunology 2006, 117(2):205-212.

37. Leffler DA, Lamont JT: Treatment of Clostridium difficile-associated disease. Gastroenterology 2009, 136(6):1899-1912.

38. Cohen SH, Gerding DN, Johnson S, Kelly CP, Loo VG, McDonald LC, Pepin J, Wilcox $\mathrm{MH}$ : Clinical practice guidelines for Clostridium difficile infection in adults: 2010 update by the society for healthcare epidemiology of America (SHEA) and the infectious diseases society of America (IDSA). Infect Control Hosp Epidemiol 2010, 31(5):431-455.

39. Liu H, Grundstrom T: Calcium regulation of GM-CSF by calmodulindependent kinase II phosphorylation of Ets1. Mol Biol Cell 2002, 13(12):4497-4507.

40. Kim JM, Lee JY, Yoon YM, Oh YK, Youn J, Kim YJ: NF-kappa B activation pathway is essential for the chemokine expression in intestinal epithelial cells stimulated with Clostridium difficile toxin A. Scand J Immunol 2006, 63(6):453-460

41. Chae S, Eckmann L, Miyamoto Y, Pothoulakis C, Karin M, Kagnoff MF: Epithelial cell I kappa B-kinase beta has an important protective role in Clostridium difficile toxin A-induced mucosal injury. J Immunol 2006, 177(2):1214-1220. 
42. Whitmarsh AJ, Davis RJ: Transcription factor AP-1 regulation by mitogen-activated protein kinase signal transduction pathways. J Mol Med (Berl) 1996, 74(10):589-607

43. McFarland LV, Elmer GW, Surawicz CM: Breaking the cycle: treatment strategies for 163 cases of recurrent Clostridium difficile disease. Am J Gastroenterol 2002, 97(7):1769-1775.

44. Pepin J, Alary ME, Valiquette L, Raiche E, Ruel J, Fulop K, Godin D, Bourassa C: Increasing risk of relapse after treatment of Clostridium difficile colitis in Quebec, Canada. Clin Infect Dis 2005, 40(11):1591-1597.

45. Kelly CP, LaMont JT: Clostridium difficile-more difficult than ever. N Engl J Med 2008, 359(18):1932-1940.

46. Choi HK, Kim KH, Lee SH, Lee SJ: Risk factors for recurrence of Clostridium difficile infection: effect of vancomycin-resistant enterococci colonization. J Korean Med Sci 2011, 26(7):859-864.

47. Louie TJ, Miller MA, Mullane KM, Weiss K, Lentnek A, Golan Y, Gorbach S, Sears $P$, Shue YK: Fidaxomicin versus vancomycin for Clostridium difficile infection. N Engl J Med 2011, 364(5):422-431.

48. Cornely OA, Crook DW, Esposito R, Poirier A, Somero MS, Weiss K, Sears P, Gorbach S: Fidaxomicin versus vancomycin for infection with Clostridium difficile in Europe, Canada, and the USA: a double-blind, non-inferiority, randomised controlled trial. Lancet Infect Dis 2012, 12(4):281-289.

49. Lupse M, Flonta M, Cioara A, Filipescu I, Todor N: Predictors of first recurrence in Clostridium difficile-associated disease. A study of 306 patients hospitalized in a Romanian tertiary referral center. J Gastrointestin Liver Dis 2013, 22(4):397-403.

50. Biller JA, Katz AJ, Flores AF, Buie TM, Gorbach SL: Treatment of recurrent Clostridium difficile colitis with Lactobacillus GG. J Pediatr Gastroenterol Nutr 1995, 21(2):224-226.

51. Wullt M, Hagslatt ML, Odenholt I: Lactobacillus plantarum 299v for the treatment of recurrent Clostridium difficile-associated diarrhoea: a double-blind, placebo-controlled trial. Scand J Infect Dis 2003, 35(6-7):365-367.

52. Perdigon G, Maldonado Galdeano C, Valdez JC, Medici M: Interaction of lactic acid bacteria with the gut immune system. Eur J Clin Nutr 2002, 56(Suppl 4):S21-S26.

53. van Baarlen $P$, Troost F, van der Meer C, Hooiveld G, Boekschoten M Brummer RJ, Kleerebezem M: Human mucosal in vivo transcriptome responses to three lactobacilli indicate how probiotics may modulate human cellular pathways. Proc Natl Acad Sci U S A 2010, 108(Suppl 1):4562-4569.

54. Kim Y, Kim SH, Whang KY, Kim YJ, Oh S: Inhibition of Escherichia coli 0157: $\mathrm{H} 7$ attachment by interactions between lactic acid bacteria and intestinal epithelial cells. J Microbiol Biotechnol 2008, 18(7):1278-1285.

55. Pattani R, Palda VA, Hwang SW, Shah PS: Probiotics for the prevention of antibiotic-associated diarrhea and Clostridium difficile infection among hospitalized patients: systematic review and meta-analysis. Open Med 2013, 7(2):e56-e67.

56. Versalovic J, lyer C, Ping Lin Y, Huang Y, Dobrogosz W: Commensal-derived probiotics as anti-inflammatory agents. Microb Ecol Health Dis 2008, 20:86-93.

57. Oezguen N, Power TD, Urvil P, Feng H, Pothoulakis C, Stamler JS, Braun W, Savidge TC: Clostridial toxins: sensing a target in a hostile gut environment. Gut Microbes 2012, 3(1):35-41.

58. Imaoka A, Shima T, Kato K, Mizuno S, Uehara T, Matsumoto S, Setoyama H, Hara T, Umesaki Y: Anti-inflammatory activity of probiotic Bifidobacterium: enhancement of IL-10 production in peripheral blood mononuclear cells from ulcerative colitis patients and inhibition of IL-8 secretion in HT-29 cells. World J Gastroenterol 2008, 14(16):2511-2516.

59. Mukaida N, Okamoto S, Ishikawa Y, Matsushima K: Molecular mechanism of interleukin-8 gene expression. J Leukoc Biol 1994, 56(5):554-558.

60. Lee JY, Park HR, Oh YK, Kim YJ, Youn J, Han JS, Kim JM: Effects of transcription factor activator protein-1 on interleukin-8 expression and enteritis in response to Clostridium difficile toxin A. J Mol Med 2007, 85(12):1393-1404.

61. Ma D, Forsythe $P$, Bienenstock J: Live Lactobacillus rhamnosus [corrected] is essential for the inhibitory effect on tumor necrosis factor alpha-induced interleukin-8 expression. Infect Immun 2004, 72(9):5308-5314.

62. Mumy KL, Chen X, Kelly CP, McCormick BA: Saccharomyces boulardii interferes with Shigella pathogenesis by postinvasion signaling events. Am J Physiol Gastrointest Liver Physiol 2008, 294(3):G599-G609.
63. Dahan S, Dalmasso G, Imbert V, Peyron JF, Rampal P, Czerucka D: Saccharomyces boulardii interferes with enterohemorrhagic Escherichia coli-induced signaling pathways in T84 cells. Infect Immun 2003, 71(2):766-773.

64. Dalmasso G, Loubat A, Dahan S, Calle G, Rampal P, Czerucka D: Saccharomyces boulardii prevents TNF-alpha-induced apoptosis in EHEC-infected T84 cells. Res Microbiol 2006, 157(5):456-465.

65. Sougioultzis S, Simeonidis S, Bhaskar KR, Chen X, Anton PM, Keates S, Pothoulakis C, Kelly CP: Saccharomyces boulardii produces a soluble anti-inflammatory factor that inhibits NF-KB-mediated IL-8 gene expression. Biochem Biophys Res Commun 2006, 343(1):69-76.

66. Yan F, Cao H, Cover TL, Whitehead R, Washington MK, Polk DB: Soluble proteins produced by probiotic bacteria regulate intestinal epithelial cell survival and growth. Gastroenterology 2007, 132(2):562-575.

67. Thomas CM, Hong T, van Pijkeren JP, Hemarajata P, Trinh DV, Hu W, Britton RA, Kalkum M, Versalovic J: Histamine derived from probiotic Lactobacillus reuteri suppresses TNF via modulation of PKA and ERK signaling. PLoS One 2012, 7(2):e31951.

68. Kelly CR, de Leon L, Jasutkar N: Fecal microbiota transplantation for relapsing Clostridium difficile infection in 26 patients: methodology and results. J Clin Gastroenterol 2012, 46(2):145-149.

69. Jorup-Ronstrom C, Hakanson A, Sandell S, Edvinsson O, Midtvedt T, Persson AK, Norin E: Fecal transplant against relapsing Clostridium difficile-associated diarrhea in 32 patients. Scand J Gastroenterol 2012, 47(5):548-552.

70. Belanger SD, Boissinot M, Clairoux N, Picard FJ, Bergeron MG: Rapid detection of Clostridium difficile in feces by real-time PCR. J Clin Microbiol 2003, 41(2):730-734.

71. NCCLS: Methods for Antimicrobial Susceptibility Testing of Anaerobic Bacteria; Approved Standard-Sixth Edition, NCCLS document M11-A6 [ISBN 1-56238-517-8]. 940 West Valley Road, Suite 1400, Wayne, Pennsylvania19087-1898 USA: NCCLS; 2004.

72. Taweechotipatr M, Iyer C, Spinler JK, Versalovic J, Tumwasorn S: Lactobacillus saerimneri and Lactobacillus ruminis: novel human-derived probiotic strains with immunomodulatory activities. FEMS Microbiol Lett 2009, 293(1):65-72

73. Pfaffl MW: A new mathematical model for relative quantification in real-time RT-PCR. Nucleic Acids Res 2001, 29(9):e45.

doi:10.1186/1471-2180-14-177

Cite this article as: Boonma et al:: Lactobacillus rhamnosus L34 and Lactobacillus casei L39 suppress Clostridium difficile-induced IL-8 production by colonic epithelial cells. BMC Microbiology 2014 14:177.

\section{Submit your next manuscript to BioMed Central and take full advantage of:}

- Convenient online submission

- Thorough peer review

- No space constraints or color figure charges

- Immediate publication on acceptance

- Inclusion in PubMed, CAS, Scopus and Google Scholar

- Research which is freely available for redistribution 